\title{
Penilaian Kematangan Proses Pengembangan Perangkat Lunak Menggunakan Capability Maturity Model Integration Roadmaps.
}

\author{
Muhammad Isa Wibisono $^{1}$, Karmilasari Karmilasari ${ }^{2}$, A'ang Subiyakto ${ }^{2}$
}

\begin{abstract}
Pengembangan produk perangkat lunak merupakan salah satu faktor penting bagi organisasi untuk menghasilkan layanan produk digital yang berdampak pada digitalisasi proses pengembangannya. Banyak organisasi sistem informasi di Indonesia menghadapi tujuan itu dan berusaha mengevaluasi proses pengembangan perangkat lunak (PPL) dibuktikan dengan pembahasan penelitian tentang topik tingkat kematangan. Dalam penelitian ini dilakukan pada salah satu organisasi perusahaan telekomunikasi Indonesia sebagai penyedia produk digital. Hal ini bertujuan untuk menilai tingkat kematangan proses PPL saat ini sebagai titik awal peningkatan proses pengembangan organisasi untuk menghasilkan kualitas produk terbaik tanpa cacat. Organisasi perlu menilai dan mengevaluasi tingkat kematangan dalam meningkatkan dan kualitas produk serta analisis kematangan dapat digunakan untuk mengungkap kelemahan proses. Hasilnya, organisasi saat ini pada maturity level 2 (ML2) atau Managed, sedangkan untuk ML3 belum terpenuhi semua process area dengan pendekatan CMMI Roadmaps sebagai langkah berikutnya untuk mencapai maturity level 3 (ML3). Beberapa rekomendasi juga diusulkan untuk meningkatkan sisa process area yang belum memenuhi specific process
\end{abstract}

Keywords - CMMI for Development, CMMI Roadmpas, Maturity Level, SPI

\section{Pendahuluan}

$\mathrm{P}$ engembangan produk perangkat lunak merupakan salah satu faktor penting bagi organisasi untuk menghasilkan layanan produk digital yang berdampak pada digitalisasi proses pengembangannya [1]. Berdasarkan publikasi laporan organisasi Hootsuite tahun 2019, trafik pengguna internet di Indonesia mencapai 150 juta pengguna, yang mempunyai penetrasi pasar sebesar $56 \%$ terhadap jumlah penduduk Indonesia [2].

Hal ini menjadi tantangan kebijakan organisasi penyedia layanan digital untuk memasarkan dan menyampaikan produk perangkat lunak kepada pelanggan secara cepat dan tepat. Oleh karena itu, perbaikan proses pengembangan perangkat lunak yang berkelanjutan diperlukan sebagai upaya mempertahankan atau bahkan meningkatkan nilai strategis sistem informasi (SI) dalam mencapai keberhasilan organisasi bisnis dan eksekutif perusahaan [3].

Saat ini, banyak organisasi SI di Indonesia menghadapi tujuan itu dan berusaha mengevaluasi proses pengembangan

Received: 09 Febuari 2020; Revised: 11 Juli 2020; Accepted: 8 Nopember 2020

'M.I. Wibisono, Program Magister Teknologi dan Rekayasa Universitas Gunadarma, Indonesia (e-mail: isazowa@gmail.com) perangkat lunak (PPL) dibuktikan dengan pembahasan penelitian tentang topik tingkat kematangan.

Oleh karena itu, dalam penelitian ini dilakukan pada salah satu organisasi dalam perusahaan telekomunikasi Indonesia sebagai penyedia produk digital. Hal ini bertujuan untuk menilai tingkat kematangan proses PPL saat ini sebagai titik awal peningkatan proses pengembangan untuk menghasilkan kualitas produk terbaik tanpa cacat.

Meskipun beberapa proses telah dilakukan peningkatan berkelanjutan, namun organisasi masih mengalami mengalami banyak kekurangan dalam penyampaian layanan produk digital. Berdasarkan catatan insiden 6 bulan terakhir, dilaporkan beberapa cacat produk yang sudah dipasarkan.

Menurut von Wangeheim, Anacleto and Salviano, 2006, bahwa kriteria untuk menghasilkan produk dengan kualitas sesuai harapan harus memenuhi tiga kriteria, yaitu tepat waktu, tepat sasaran, dan tepat biaya [4].

Oleh karena itu untuk memudahkan analisis dalam penilaian tingkat akurasi perbaikan proses, maka dalam penelitian ini menggunakan acuan kerangka kerja Capability Maturity Model Integration for Development (CMMI-DEV) versi 1.3 dengan pendekatan CMMI Roadmaps. Selanjutnya, hasil analisis proses saat ini, diusulkan rekomendasi sebagai dasar pengembangan produk di masa mendatang menjadi lebih baik [5].

\section{A. Pertanyaan Penelitian}

Berdasarkan identifikasi masalah pada penjelasan sebelumnya, penelitian ini bertujuan untuk menjawab beberapa pertanyaan sebagai berikut:

1) Bagaimana bentuk evaluasi kematangan atau kemampuan proses PPL organisasi saat ini?

2) Apa saja usulan atau rekomendasi yang memungkinkan diterapkan organisasi?

\section{LITERATUR REVIEW}

A. Penelitian Terkait

Penelitian yang dilakukan Mewengkang dan Djamen ini untuk mengukur dan meningkatkan kualitas sistem informasi akademik di Universitas Negeri Manado menggunakan metodologi CMMI. Diharapkan juga dapat meningkatkan kinerja dalam sebuah proyek, divisi atau seluruh organisasi di universitas [6].

${ }^{2}$ K. Karmilasari, Departemen Pengembangan Komputerisasi Universitas Gunadarma, Indonesia (e-mail: karmila@staff.gunadarma.ac.id)

${ }^{3}$ A. Subiyakto, Prodi Sistem Informasi Universitas Islam Negeri (UIN) Syarif Hidayatullah Jakarta, Indonesia (e-mail: aang_subiyakto@uinjkt.ac.id) 
Penelitian Widodo ini dilakukan untuk mengetahui tingkat kematangan dan tingkat kapabilitas proses pengembangan perangkat lunak pada unit Virtual Team Development (VTD) [7].

Penelitian Kurniawati, Saputra dan Rachmadi ini menilai tingkat kematangan proses pengembangan perangkat lunak pada Divisi Pengembangan Produk perusahaan dimulai dari proses dasar pengelolaan proyek menggunakan framework CMMI for Development versi 1.3 [8].

Penelitian Mahmud, Rachmadi dan Saputra menilai tingkat kapabilitas proses pengembangan produk pada salah satu divisi di perusahaan menggunakan Capability Maturity Model Integration (CMMI). Hasil penelitian ini mencapai tujuannya, yaitu mampu mendefinisikan tingkat kapabilitas. Dari hasil penilaian tersebut dilakukan analisis lanjutan dalam memberi solusi pada perusahaan untuk meningkatkan tingkat kapabilitas ke level berikutnya [9].

Penelitian Torrecilla-Salinas dkk., ini mengusulkan rangkain metode Agile dalam mencapai semua proses kematangan menggunakan CMMI-DEV level 3 secara umum dan tujuan spesifik pada studi kasus web environment. Hasil penelitian ini mencapai tujuannya, yaitu model yang digunakan sepenuhnya kompatibel pada kapabilitas level 3. Namun, tetap perlu mengevaluasi Agile pada Scrum Framework dalam studi kasus melalui penilaian formal sesuai petunjuk kapabilitas perangkat lunak [10].

Penelitian Ayyagari dan Atoum ini menerapkan dan menyederhanakan tingkat kapabilitas pada model pengembangan perangkat lunak Spiral untuk mencapai kematangan kapabilitas level 2. Hal ini mempunyai tujuan utama untuk mengurangi biaya dan meningkatkan produktivitas dengan menggunakan standar dan praktik terbaik [11].

Berdasarkan literatur terkait, ada beberapa penelitian yang didedikasikan untuk menilai tingkat kematangan. Studi mengenai tingkat kematangan dapat dilakukan dengan menggunakan artefak yang ada, baik dari dokumen atau sistem pendukung proses pengembangan sebagai referensi pemetaan process area pada CMMI-Dev 1.3 [12].

B. Capability Maturity Model Integration (CMMI).

Dalam panduan CMMI-Dev versi 1.3 Carniege Mellon University, (2010), CMMI for Development adalah model referensi yang mencakup kegiatan pengembangan produk dan layanan. Organisasi dari banyak industri, termasuk penerbangan, perbankan, perangkat keras komputer, perangkat lunak, pertahanan, manufaktur mobil, dan telekomunikasi, menggunakan CMMI for Development [12].

Dengan demikian, kerangka kerja CMMI dapat digunakan untuk meningkatkan proses pengembangan perangkat lunak menjadi lebih baik. Kerangka kerja tersebut merupakan kumpulan komponen yang digunakan untuk membangun model CMMI, pelatihan CMMI, dan penilaian CMMI.
Terdapat 4 domain pada 22 process area (PA) dalam CMMI-DEV antara lain:

1) Process management. Domain proses ini mencakup beberapa aktivitas lintas proyek yang berhubungan dengan mendefinisikan, perencanaan, deploying, implementasi, pemantauan, pengendalian, penilaian, pengukuran, dan peningkatan proses-proses. PA yang terlibat adalah: Organizational Process Definition (OPD), Organizational Process Focus (OPF), Organizational Performance Management (OPM), Organizational Process Performance (OPP), dan Organizational Training (OT).

2) Project Management. Domain proses ini mencakup aktivitas manajemen proyek yang berhubungan dengan perencanaan, pemantauan, dan pengendalian proyek. PA yang terlibat adalah: Integrated Project Management (IPM), Project Monitoring and Control (PMC), Project Planning (PP), Quantitative Project Management (QPM), Requirements Management (REQM), Risk Management (RSKM), dan Supplier Agreement Management (SAM).

3) Engineering. Domain proses ini mencakup aktivitas pengembangan dan pemeliharaan. PA yng terlibat adalah: Product Integration (PI), Requirements Development (RD), Technical Solution (TS), Validation (VAL), dan Verification (VER).

4) Support. Domain proses ini mencakup beberapa aktivitas yang mendukung pengembangan dan pemeliharaan. PA yang terlibat adalah: Causal Analysis and Resolution (CAR), Configuration Management (CM), Decision Analysis and Resolution (DAR), Measurement and Analysis (MA), dan Process and Product Quality Assurance (PPQA).

\section{CMMI Roadmaps}

CMMI Roadmaps merupakan alat untuk membantu organisasi yang ingin menggunakan representasi berkelanjutan [13]. Roadmaps mampu memilih PA yang akan diimplementasi berdasarkan tujuan dan masalah peningkatan PPL yang ingin diselesaikan organisasi [14].

Menurut Hakim, (2015), bahwa organisasi lebih baik menggunakan alat ini saat baru memulai menentukan titik awal peningkatan proses dalam menentukan tingkat kematangan CMMI [15]. Pada petunjuk penilaian kematangan disediakan lima roadmaps antara lain: project, product, product integration, process dan measurement roadmap.

D. Ekuivalensi Tingkat Maturity dan Capability

Pada setiap tingkat, baik maturity maupun capability, terdapat PA yang harus dipenuhi, sehingga suatu organisasi dikatakan memiliki maturity level ataupun capability level.

Berikut ini merupakan ekuivalen atau persamaan PA yang harus dicapai organisasi apabila ingin mencapai tingkat maturity atau capability level yang diinginkan beserta perbandingannya. 


\begin{tabular}{|c|c|c|c|}
\hline Name & Abbr. & ML & $C L 1 \quad C L 2$ \\
\hline Configuration Management & $\mathrm{CM}$ & 2 & \multirow{18}{*}{$\begin{array}{c}\text { Target } \\
\text { Profile } 2\end{array}$} \\
\hline Measurement and Analysis & MA & 2 & \\
\hline Project Monitoring and Control & PMC & 2 & \\
\hline Project Planning & PP & 2 & \\
\hline Process and Product Quality Assurance & PPQA & 2 & \\
\hline Requirements Management & REQM & 2 & \\
\hline Supplier Agreement Management & SAM & 2 & \\
\hline Decision Analysis and Resolution & DAR & 3 & \\
\hline Integrated Project Management & IPM & 3 & \\
\hline Organizational Process Definition & OPD & 3 & \\
\hline Organizational Process Focus & OPF & 3 & \\
\hline Organizational Training & OT & 3 & \\
\hline Product Integration & PI & 3 & \\
\hline Requirements Development & RD & 3 & \\
\hline Risk Management & RSKM & 3 & \\
\hline Technical Solution & TS & 3 & \\
\hline Validation & VAL & 3 & \\
\hline Verification & VER & 3 & \\
\hline Organizational Process Performance & OPP & 4 & \multirow{2}{*}{$\begin{array}{c}\text { Target } \\
\text { Profile } 4\end{array}$} \\
\hline Quantitative Project Management & QPM & 4 & \\
\hline Causal Analysis and Resolution & CAR & 5 & \multirow{2}{*}{$\begin{array}{c}\text { Target } \\
\text { Profile } 5\end{array}$} \\
\hline Organizational Performance Management & OPM & 5 & \\
\hline
\end{tabular}

Gambar 1. Ekuivalen Process Area Maturity dan Capability Level [12]

\section{Metode PenElitian}

Metode yang digunakan dalam penelitian ini merupakan studi kasus kualitatif yang dibagi dalam empat tahap.

Pertama, pengumpulan data awal, yaitu menentukan masalah dengan mendiskusikan masalah dan merumuskan permasalahan; kedua, melakukan kajian pustaka untuk mengelaborasi perspektif studi terbaru sehubungan dengan masalah penelitian dan merancang tahapan penelitian; ketiga, menentukan kontribusi area proses dalam menganalisis artefak yang ada; keempat, menilai tingkat kematangan proses.

Sebagaimana konteks rekayasa perangkat lunak, dalam studi kasus ini menggunakan pendekatan "exploratory and improving" [16] dan action research (AR) [17].

Tahap exploratory dilakukan melalui wawancara dan observasi dalam upaya menemukan dan mengelaborasi "apa yang terjadi” pada proses PPL organisasi saat ini. Sedangkan tahap improving, mengusulkan rekomendasi yang memungkinkan untuk perbaikan proses PPL berikutnya.

Sesuai dengan pedoman dari Runeson \& Höst, (2009a) terdapat dua sumber data yang digunakan yaitu data primer dan data sekunder sebagai berikut [18]:

1) Data primer diperoleh dari hasil tanya jawab atau wawancara dan diskusi dengan eksekutif untuk mengkonfirmasi dalam penentuan tingkat kapabilitas sebagai target organisasi [19], [20].

2) Data sekunder didapat dengan melakukan studi pustaka dan studi dokumen organisasi mengenai proses PPL. Hal ini merupakan analisis kualitatif untuk mendapat kesimpulan dan bukti yang kuat dalam memberikan usulan rekomendasi [19].

Berikut ini merupakan tahap penelitian secara rinci dalam bentuk aktifitas sekuensial.

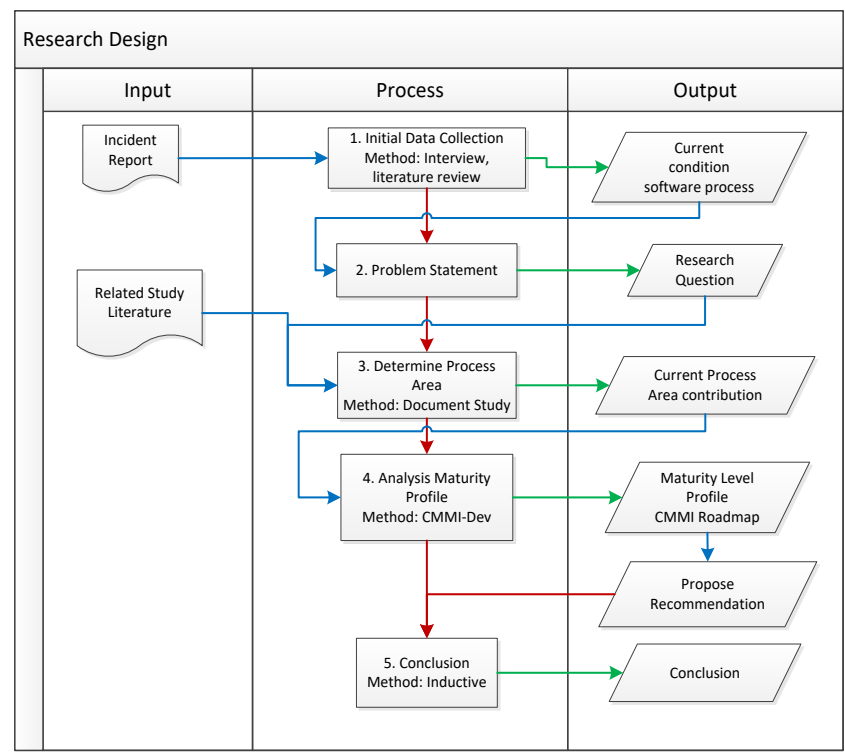

Gambar 2. Tahapan Penelitian

\section{HASIL DAN PEMBAHASAN}

A. Analisis Specific Practice pada Proses PPL Organisasi Dalam penelitian ini, memahami proses terkait hubungan antar process area dalam proses PPL saat ini.

Penentuan process area (PA) yang terlibat dalam organisasi membutuhkan analisis antara praktik proses PPL berjalan dengan specific practice (SP) pada 22 process area CMMI. Oleh karena itu, untuk menentukan PA setiap SP dilakukan dengan menyesuaikan hasil analisis dokumen atau sistem pendukung yang dimiliki oleh organisasi.

Apabila setiap SP pada suatu PA tidak terpenuhi, maka process area tersebut untuk saat ini tidak dipilih sebagai prioritas yang akan ditingkatkan atau dapat dihilangkan (eliminasi). Dalam hal ini PA Supplier Agreement Management (SAM), karena produk yang dihasilkan organisasi berupa produk perangkat lunak atau intangible product [8].

Namun, untuk process area Risk Management (RSKM) dapat dipertimbangkan untuk dimiliki organisasi. Akan tetapi dalam penelitian ini, PA tersebut juga akan dihilangkan, karena belum ada praktik tersebut pada proses PPL berjalan. Tabel 1.

Hasil Analisis Praktik Specific Practice pada Setiap Process Area

\begin{tabular}{llrr}
\hline \hline No & \multicolumn{1}{c}{ Process Area } & SP Terpenuhi & Total SP \\
\hline 1 & Causal Analysis and Resolution (CAR) & 3 & 5 \\
2 & Configuration Management (CM) & 7 & 7 \\
3 & Decision Analysis and Resolution (DAR) & 3 & 6 \\
4 & Integrated Project Management (IPM) & 6 & 9 \\
\hline \hline
\end{tabular}




\begin{tabular}{llrr}
\hline \hline 5 & Measurement and Analysis (MA) & 8 & 8 \\
6 & Organizational Process Definition (OPD) & 7 & 7 \\
7 & Organizational Process Focus (OPF) & 4 & 9 \\
8 & Organizational Performance Management (OPM) & 8 & 10 \\
9 & Organizational Process Performance (OPP) & 5 & 5 \\
10 & Organizational Training (OT) & 5 & 7 \\
11 & Product Integration (PI) & 7 & 9 \\
12 & Project Monitoring and Control (PMC) & 10 & 10 \\
13 & Project Planning (PP) & 14 & 14 \\
14 & Process and Product Quality Assurance (PPQA) & 4 & 4 \\
15 & Quantitative Project Management (QPM) & 5 & 7 \\
16 & Requirements Development (RD) & 9 & 10 \\
17 & Requirements Management (REQM) & 5 & 5 \\
18 & Risk Management (RSKM) & 0 & 7 \\
19 & Supplier Agreement Management (SAM) & 0 & 6 \\
20 & Technical Solution (TS) & 5 & 8 \\
21 & Validation (VAL) & 5 & 5 \\
22 & Verification (VER) & 5 & 8 \\
Total & & 125 & 166 \\
\hline \hline
\end{tabular}

Hasil analisis pada Tabel 1, menyatakan prioritas process area (PA) sedikitnya memiliki satu SP yang terpenuhi. Dengan demikian, organisasi dalam proses PPL saat ini mempunyai 20 dari 22 PA yang ada.

Oleh karena itu, menurut analisis ekuivalensi praktik SP dari Tabel 1, tingkat kematangan organisasi dapat diidentifikasi sebagai Maturity Level 2 (ML2). Hal ini karena semua PA pada ML2 dapat memenuhi semua SP, sedangkan untuk ML3 tidak memenuhi semua PA [21]. Semua PA pada ML2 dapat dijelaskan dalam Tabel 2 berikut ini.

Tabel 2.

Tingkat Kematangan Organisasi Saat Ini

\begin{tabular}{ll}
\hline Process Area & $\begin{array}{l}\text { Maturity } \\
\text { Level }\end{array}$ \\
\hline Requirements Management (REQM) & 2-Managed \\
Project Planning (PP) & 2-Managed \\
Project Monitoring and Control (PMC) & 2-Managed \\
Measurement and Analysis (MA) & 2-Managed \\
Process and Product Quality Assurance & 2-Managed \\
(PPQA) & \\
Configuration Management (CM) & 2-Managed \\
Supplier Agreement Management (SAM) & Deleted \\
\hline \hline
\end{tabular}

Namun demikian, berdasarkan Tabel 2, hasil analisis saat ini dan wawancara dengan manajemen eksekutif, mereka menghindari perubahan ekstrim untuk mencapai ML3.

Sehingga, merujuk pada pedoman CMMI-Dev versi 1.3, dapat menggunakan pendekatan CMMI Roadmaps untuk mencapai ML3 [13].

B. Penilaian Tingkat Kematangan pada CMMI Roadmaps

Hasil dari wawancara dengan manajemen eksekutif, menentukan prioritas roadmaps, yaitu project roadmap dan product roadmap. Sehingga PA yang dipilih untuk analisis tingkat kematangan meliputi: Project Planning (PP), Project Monitoring and Control (PMC), Requirements Management
(REQM), Configuration Management (CM), Process and Product Quality Assurance (PPQA), Requirements Development (RD), Technical Solution (TS), Verification (VER).

Tabel 3.

Tingkat Kematangan pada CMMI Roadmaps

\begin{tabular}{cll}
\hline \hline No & \multicolumn{1}{c}{ Process Area } & \multicolumn{1}{c}{$\begin{array}{c}\text { Maturity } \\
\text { Level }\end{array}$} \\
\hline 1 & $\begin{array}{l}\text { Project Planning (PP) } \\
\text { Project Monitoring and Control } \\
\text { (PMC) }\end{array}$ & $\begin{array}{l}\text { 2-Managed } \\
\text { 2-Managed }\end{array}$ \\
3 & $\begin{array}{l}\text { Requirements Management } \\
\text { (REQM) }\end{array}$ & 2-Managed \\
4 & $\begin{array}{l}\text { Configuration Management } \\
\text { (CM) }\end{array}$ & 2-Managed \\
5 & $\begin{array}{l}\text { Process and Product Quality } \\
\text { Assurance (PPQA) }\end{array}$ & 2-Managed \\
6 & $\begin{array}{l}\text { Requirements Development } \\
\text { (RD) }\end{array}$ & 0-Inclomplete \\
7 & Technical Solution (TS) & 0-Inclomplete \\
8 & Verification (VER) & 0-Inclomplete \\
\hline \hline
\end{tabular}

Terdapat 3 PA yang tidak memenuhi semua SP, yaitu Requirement Development (RD), Technical Solution (TS) dan Verification (VER). Tabel 3 di bawah ini menggambarkan prosentase kesenjangan yang harus dicapai untuk SP saat ini sesuai dengan CMMI Roadmaps.

$$
\text { Tabel } 4 .
$$

Analisis Kesenjangan (Gap) CMMI Roadmaps

\begin{tabular}{rrrrr}
\hline \hline PA & Total SP & SP Terpenuhi & Prosentase & Gap \\
& & & & \\
\hline RD & 10 & 9 & $90 \%$ & $10 \%$ \\
TS & 8 & 5 & $62,50 \%$ & $37,50 \%$
\end{tabular}




\begin{tabular}{lllll}
\hline \hline VER & 8 & 5 & $62,50 \%$ & $37,50 \%$ \\
\hline
\end{tabular}

\section{Analisis Kesenjangan Process Area}

Berdasarkan analisis lanjutan untuk tiga PA tersebut, terdapat penyebab masalah yang mempunyai kemiripan satu sama lain terkait kesenjangan PA yang tidak memenuhi semua SP, yaitu process area RD, TS, dan VER. Terdapat empat faktor sumber masalah yang mempunyai kemiripan, antara lain:

1) Proses tidak ada. Process area TS dapat teridentifikasi masalah: Pertama, menulis dan menganalisis setiap alternatif yang ditemukan dalam dokumen. Kedua, analisis mana yang lebih baik, membangun sendiri, membeli, atau mendaur ulang produk yang ada. Process area VER mempunyai penyebab masalah utama: Pentingnya melakukan pemeriksaan lebih lanjut hasil verifikasi dan melakukan analisis untuk menghindari cacat produk.

2) Dokumen tidak lengkap. Process area RD teridentifikasi sumber masalah: Pentingnya membangun komunikasi lintas fungsi mengenai risiko produk dan analisis yang menentukan daur ulang, biaya, skema produk. Process area TS teridentifikasi sumber masalah: Kurangnya penentuan biaya, manfaat, dan risiko antara alternatif produk, pemantauan perubahan produk selama proses pengembangan perangkat lunak. Process area VER teridentifikasi sumber masalah: Tidak ada pengembangan analisis pada hasil pengujian untuk menghindari cacat produk.

3) Tidak tercakup dalam sistem pendukung. Process area $R D$ teridentifikasi sumber masalah: Mendefinisikan laporan produk dalam sistem pendukung yang dipakai saat ini untuk analisis kebutuhan dan risiko terhadap pengembangan produk. Process area TS teridentifikasi sumber masalah: Laporan produk yang diperlukan dalam sistem pendukung untuk analisis solusi alternatif dan membuat keputusan untuk daur ulang atau membuat pengembangan produk baru. Process area VER teridentifikasi sumber masalah: kebutuhan untuk menganalisis hasil pengujian produk pada sistem pendukung untuk memastikan kualitas produk.

4) Sumberdaya kurang pengetahuan. Process area RD teridentifikasi sumber masalah: Pertama, lemahnya kolaborasi dengan tim lain yang relevan untuk koordinasi kegiatan pengembangan yang dibutuhkan. Kedua, penting untuk menganalisis kebutuhan biaya, skema produk, dan risiko pengembangan perangkat lunak. Process area TS teridentifikasi sumber masalah: Pertama, melakukan analisis alternatif untuk memberikan solusi bagi pelanggan. Kedua, melakukan analisis produk yang ada untuk keputusan rekayasa ulang atau membangun kembali pengembangan produk.

D. Usulan Rekomendasi Perbaikan Proses PPL

Berdasarkan pengumpulan data dan hasil penilaian dalam pendekatan CMMI Roadmaps, untuk mencapai CMMI ML3, setiap praktik harus dilaksanakan secara menyeluruh.

Hal ini dapat dilakukan dengan tujuan agar tidak ada kesenjangan (gap) antara praktik yang dilakukan dalam organisasi. Berikut ini adalah usulan rekomendasi sebagai solusi terhadap sumber masalah:

1) Proses tidak ada. Dapat dilakukan dengan membuat dan mengembangkan standar operasi baru untuk setiap tahap proses PPL, mendistribusikan standar baru ke semua tim dan menjadi tanggung jawab mengenai apa yang perlu dilakukan [22].

2) skomendasi pada masalah ini. Pertama, menerapkan peer programming atau melakukan sharing knowledge, pelatihan formal [23].

Oleh karena itu, jika organisasi melaksanakan semua rekomendasi tersebut, maka hal itu akan memperoleh beberapa manfaat terkait peningkatan proses PPL [24].

\section{PENUTUP}

Dalam penelitian ini menyajikan dua kontribusi. Pertama, analisis tingkat kematangan proses PPL organisasi saat ini. Kedua, mengusulkan rekomendasi mengenai sumber masalah yang terjadi pada organisasi. Berdasarkan hasil evaluasi dan prioritas CMMI Roadmaps dapat mengungkapkan beberapa fakta.

Pertama, tingkat kematangan organisasi saat ini pada Maturity Level 2 atau Managed. Hal ini karena 6 PA terpenuhi pada evaluasi ML2 CMMI-Dev 1.3. Dengan process area REQM, PP, PMC, MA, PPQA dan CM telah terimplementasi pada dokumen dan sistem pendukung terkait dengan semua specific practice (SP) dan generic practice.

Kedua, organisasi menggunakan pendekatan CMMI Roadmaps untuk mencapai maturity level 3 (ML3). Terdapat tiga PA tidak terpenuhi semua SP, yaitu pada PA RD, TS, dan VER. Berdasarkan hasil analisis, terdapat 4 usulan rekomendasi untuk meningkatkan kelengkapan SP. Jika organisasi menerapkan rekomendasi tersebut secara menyeluruh, maka akan mencapai ML3 dengan pendekatan CMMI Roadmaps.

\section{REFERENSI}

[1] M. I. Wibisono, R. S. Utami, F. Ridha, and A. B. Setyawan, "The Automated Test Software Design and Cost Benefit in Sanity Testing," in Proceeding UG Economics Faculty International Conference (UGEFIC), 2018, pp. 1-10.

[2] Hootsuite Media Inc, "DIGITAL 2019," 2019.

[3] J. W. Satzinger, R. B. Jackson, and S. D. Burd, Systems Analysis \& Design in a Changing World, Fifth Edition. 2012.

[4] C. G. von Wangeheim, A. Anacleto, and C. F. Salviano, "Helping Small Companies Assess Software Processes," IEEE Softw., vol. 23, no. 1, pp. 91-98, 2006.

[5] P. Griesberger Susanne Leist Gregor Zellner, "Analysis of Techniques for Business Process Improvement," in European Conference on Information Systems, 2011, pp. 1-8.

[6] A. Mewengkang and A. C. Djamen, "Pemanfaatan Capability Maturity Model Integration ( CMMI ) Untuk Meningkatkan Kualitas Perangkat Lunak ( Studi Kasus: Sistem Informas Akademik Universitas Negeri Manado," Eng. Educ. J., vol. 4, no. 3, pp. 2-6, 2016.

[7] W. Widodo, "Evaluasi Proses Pengembangan Perangkat Lunak pada Virtual Team Development Menggunakan CMMI Versi 1.3," J. Inform., vol. 10, no. 1, pp. 1140-1148, 2016.

[8] I. Kurniawati, M. C. Saputra, and A. Rachmadi, "Penilaian Tingkat Kematangan Proses Pengembangan Perangkat Lunak Menggunakan Framework CMMI-Dev 1.3 Pada PT. ABC," $J$. Pengemb. Teknol. Inf. dan Ilmu Komput. Univ. Brawijaya, vol. 2 , no. 12, pp. 6457-6466, 2018.

[9] A. M. Mahmud, A. Rachmadi, and M. C. Saputra, "Penilaian Kapabilitas Pengembangan Perangkat Lunak Pada Perusahaan Pengembang Perangkat Lunak Menggunakan CMMI - DEV 1 . 3 ( Studi," J. Pengemb. Teknol. Inf. dan Ilmu Komput. Univ. Brawijaya, vol. 2, no. 11, pp. 5567-5576, 2018.

[10] C. J. Torrecilla-Salinas, J. Sedeño, M. J. Escalona, and M. Mejías, "Mapping Agile Practices to CMMI-DEV Level 3 in Web Development Environments," in 23rd International Conference on Information Systems Development, ISD 2014, 2014, pp. 348-355. 
Simplified: A spiral Software Model," Int. J. Adv. Comput. Sci. Appl., vol. 10, no. 4, pp. 445-450, 2019.

[12] C. P. T. Carniege Mellon University, "CMMI for Development, Version 1.3," 2010.

[13] J. J. Cannegieter, A. Heijstek, B. Linders, and R. van Solingen, “CMMI Roadmaps," Pittsburgh, 2008.

[14] A. Rachmaniar and W. Handrini, "Perancangan Sistem Penggajian Karyawan Berbasis Desktop pada PT. Elenbee Cipta Desain," $J$. Ilm. KOMPUTASI, vol. 18, no. 4, pp. 337-348, 2019.

[15] A. B. Hakim, "Penerapan CMMI Pada Perusahaan Kecil : Studi Kasus PT . Logix System Technology," I-STATEMENT, vol. 1, no. 4, pp. 1-14, 2015.

[16] P. Runeson and M. Höst, "Tutorial: Case studies in software engineering," in Lecture Notes in Business Information Processing, 2009, vol. 32 LNBIP, pp. 441-442.

[17] T. Gorschek and C. Wohlin, "A Model for Technology Transfer in Practice," J. IEEE Softw., vol. 23, no. 6, pp. 88-95, 2006.

[18] P. Runeson and M. Höst, "Guidelines for conducting and reporting case study research in software engineering," Empir. Softw. Eng., vol. 14, pp. 131-164, 2009.

[19] A. Hasibuan Z, Metodologi Penelitian pada Bidang Ilmu Komputer dan Teknologi Informasi. Depok: Fakultas Ilmu Komputer Universitas Indonesia, 2007.

[20] P. D. SUGIYONO, Statistika Untuk Penelitian, 11th ed. Bandung:
ALFABETA BANDUNG, 2007

[21] F. S. Silva et al., "Using CMMI together with agile software development: A systematic review," Inf. Softw. Technol., vol. 58, no. 1, pp. 20-43, 2015.

[22] V. Serrano, A. Tereso, P. Ribeiro, and M. Brito, "Standardization of Processes Applying CMMI Best Practices," Adv. Inf. Syst. Technol., vol. 206, pp. 455-467, 2013.

[23] N. M. Rodrigues and A. K. Lingappa, "Six Sigma and CMMI," IOSR J. Comput. Eng., vol. 16, no. 4, pp. 1-5, 2014.

[24] I. Solichah, M. Hamilton, P. Mursanto, C. Ryan, and M Perepletchikov, "Exploration on Software Complexity Metrics for Business Process Model and Notation," in ICACSIS 2013, 2013, pp. $978-979$.

[25] N. Ionel, "Critical Analysys of the Scrum Project Management Methodology.," Ann. Univ. Oradea, Econ. Sci. Ser., vol. 17, no. 4, pp. 435-441, 2008.

[26] M. Paasivaara, S. Durasiewicz, and C. Lassenius, "Using Scrum in Distributed Agile Development: A Multiple Case Study," 2009 Fourth IEEE Int. Conf. Glob. Softw. Eng., pp. 195-204, 2009.

[27] A. Rasnacis and S. Berzisa, "Method for Adaptation and Implementation of Agile Project Management Methodology," Procedia Comput. Sci., vol. 104, no. December 2016, pp. 43-50, 2016. 